\title{
Advantages of adjuvant chemotherapy for patients with triple-negative breast cancer at Stage II: usefulness of prognostic markers E-cadherin and Ki67
}

Shinichiro Kashiwagi ${ }^{1}$, Masakazu Yashiro ${ }^{1,2^{*}}$, Tsutomu Takashima', Naoki Aomatsu', Katsumi Ikeda ${ }^{3}$, Yoshinari Ogawa ${ }^{3}$, Tetsuro Ishikawa ${ }^{1}$ and Kosei Hirakawa ${ }^{1}$

\begin{abstract}
Introduction: Triple-negative breast cancer (TNBC), which is characterized by negativity for estrogen receptor, progesterone receptor and human epidermal growth factor receptor 2 (HER2), is a high risk breast cancer that lacks specific targets for treatment selection. Chemotherapy is, therefore, the primary systemic modality used in the treatment of this disease, but reliable parameters to predict the chemosensitivity of TNBC have not been clinically available.
\end{abstract}

Methods: A total of 190 TNBC patients who had undergone a curative resection of a primary breast cancer were enrolled. The adjuvant chemotherapy was performed for 138 (73\%) of 190 TNBC cases; 60 cases had an anthracyclin-based regimen and 78 a 5-fluorouracil-based regimen. The prognostic value of E-cadherin, Ki67 and p53 expression in the outcome of TNBC patients with adjuvant chemotherapy was evaluated by immunohistochemistry.

Results: The adjuvant therapy group, especially those with Stage II TNBC, had a more favorable prognosis than the surgery only group $(P=0.0043)$, while there was no significant difference in prognosis between the anthracyclinbased regimen and 5-fluorouracil-based regimen. Patients with E-cadherin-negative and Ki67-positive expression showed significantly worse overall survival time than those with either E-cadherin-positive or Ki67-negative expression $(P<0.001)$. Multivariate analysis showed that the combination of E-cadherin-negative and Ki67-positive expression was strongly predictive of poor overall survival $(P=0.004)$ in TNBC patients receiving adjuvant chemotherapy. In contrast, p53 status was not a specific prognostic factor.

Conclusions: Adjuvant therapy is beneficial for Stage II TNBC patients. The combination of E-cadherin and Ki67 status might be a useful prognostic marker indicating the need for adjuvant chemotherapy in Stage II TNBC patients.

Keywords: chemosensitivity, E-cadherin, Ki67, predictive marker, triple-negative breast cancer

\section{Introduction}

Breast cancer is a heterogeneous disease and is currently divided into subtypes in accordance with the status of estrogen receptor (ER), progesterone receptor (PR) and human epidermal growth factor receptor 2 (HER2) [1-3]. These subtypes display significant diversity in

\footnotetext{
* Correspondence: m9312510@med.osaka-cu.ac.jp

'Department of Surgical Oncology, Osaka City University Graduate School of Medicine, 1-4-3 Asahi-machi, Abeno-ku, Osaka, Japan

Full list of author information is available at the end of the article
}

regard to the clinical behavior, outcome and response to therapy [4-6]. One of these subtypes, triple-negative breast cancer (TNBC), which is characterized by a lack of ER, PR and HER2 expression, accounts for $10 \%$ to $20 \%$ of all breast cancers, and has a high probability of early tumor relapse after diagnosis, increased propensity to develop brain metastases, and rapid risk of death after tumor relapse [1,7-9]; adjuvant therapy is thus necessary for patients with TNBC [10]. However, since TNBC lacks specific targets for treatment selection,

\section{C) Biomed Central}


chemotherapy is the primary systemic modality used in the treatment of this disease [11].

A recent study has demonstrated that TNBC is more chemosensitive than other subtypes of breast cancer [12]. Kennedy et al. reported that patients with TNBC who underwent adjuvant chemotherapy were 52\% less likely to die compared with those who received neoadjuvant chemotherapy or no/unknown chemotherapy [13], suggesting that the benefit of primary tumor removal followed by early initiation of adjuvant therapy may be most relevant for the TNBC subgroup. Anthracyclines (epirubicin and doxorubicin), alkylating agents (cyclophosphamide), and 5-fluorouracil (5FU) are the standard of care in the treatment of breast cancer in the adjuvant setting.

The selection of patients with chemosensitive tumors before initiating chemotherapy would be important for avoiding potential therapy-related complications. Predictive factors of response would help to assess the expected individual benefit of this treatment. Different breast cancer subgroups may have different predictive markers of response to chemotherapy. Thus, it is of the highest importance to elucidate prognostic factors and key biomarkers of triple-negative cancers. Although various in vivo and in vitro approaches have been used in an attempt to predict the chemosensitivity of TNBC [14-16], reliable parameters have not been clinically available. The purpose of this study was to evaluate candidate predictive markers for chemosensitivity in TNBC.

E-cadherin, one of the cell adhesion molecules, is reported to be related to the invasion of cancer cells, and a low-level expression of E-cadherin is considered to be an indication of poor prognosis [17-22]. Although E-cadherin is one of the markers for chemosensitivity in several types of carcinomas [23-25], the significance of E-cadherin for chemosensitivity of TNBC remains unclear [25]. Ki67 has been reported to be a candidate predictive marker for chemosensitivity in all types of breast cancer $[16,26]$, but the predictive value of $\mathrm{Ki} 67$ for chemoresponse of TNBC has not been clarified. p53 status is one of the most investigated predictive biomarkers for the efficacy of anthracycline-containing chemotherapy. Despite the many studies, however, the results have been inconsistent, with some studies reporting an association between p53 expression and tumor response to neoadjuvant anthracyclines [27-29], whereas other reports have associated p53 overexpression with both resistance $[30,31]$ and sensitivity $[32,33]$ to preoperative anthracycline-containing chemotherapy. TNBC is more likely to carry TP53 gene mutations. In the present study, we evaluated the prognostic value of E-cadherin, Ki67 and p53 expression for the outcome of adjuvant chemotherapy in 190 cases of TNBC, which were culled from 1,036 cases of all types of breast carcinomas.

\section{Methods \\ Patients}

This study investigated a consecutive series of 1,063 cases of sporadic invasive breast carcinoma. Because Ecadherin is functionally silenced in invasive lobular carcinoma [34], 27 cases of invasive lobular carcinomas were excluded. Then a total of 1,036 breast cancer cases were enrolled in this study. All patients had received a curative operation of a mastectomy or a conservative surgery with axillary lymph node dissection in Osaka City University Hospital or Osaka City General Hospital from 2000 to 2006. The median follow-up time was 3.6 years (range, 0.2 to 6.0 years). Tumors were confirmed histopathologically and staged according to the TNM classification [35]. All patients who underwent breastconserving surgery were administered post-operative radiotherapy. Adjuvant chemotherapy was performed either by an anthracycline-based regimen (doxorubicin or epirubicin) or by a 5FU-based regimen in TNBC depending on the stage or risk of recurrence in accordance with the National Comprehensive Cancer Network (NCCN) guidelines [36]. This study was conducted with the consent of the ethical committee of Osaka City University, and informed consent was obtained from all subjects. Overall survival time was set in days as the period from the initial surgery.

\section{Immunohistochemistry}

Immunohistochemical study was performed as previously reported [37]. Briefly, the formalin embedded tissue sections were deparaffinized, and were heated in Target Retrieval Solution (Dako, Carpinteria, CA, USA). Sections were then incubated in $10 \%$ normal goat or rabbit serum to reduce non-specific antibody binding. Tissue sections were then incubated with each primary monoclonal antibody against ER (clone 1D5, dilution 1:80; Dako, Cambridge, UK), PR (clone PgR636, dilution 1:100; Dako), HER2 (Hercep Test, Dako), p53 (clone DO-7, dilution 1:50; Dako), Ki67 (clone MIB-1, dilution 1:00; Dako) and E-cadherin (clone $\mathrm{NCH}-38$, dilution 1:200; Dako). The slides were treated with streptavidinperoxidase reagent, and were incubated in PBS diaminobenzidine and $1 \%$ hydrogen peroxide $\mathrm{v} / \mathrm{v}$, followed by counterstaining with Mayer's hematoxylin. Positive and negative controls for each marker were used according to the supplier's data sheet (Dako). Immunohistochemical scoring was performed in a blind fashion. The cutoff for ER positivity and PR positivity was > $0 \%$ positive tumor cells with nuclear staining. HER2 was graded according to the accepted grading scheme as $0,1+, 2+$, 
$3+$ the following criteria were used for scoring: 0 , no reactivity or membranous reactivity in less than $10 \%$ of cells; $1+$, faint/barely perceptible membranous reactivity in $10 \%$ of cells or higher or reactivity in only part of the cell membrane; $2+$, weak to moderate complete or basolateral membranous reactivity in $10 \%$ of tumor cells or higher; $3+$, strong complete or basolateral membranous reactivity in $10 \%$ of tumor cells or higher. HER-2 was considered to be positive if immunostaining was $3+$ or if a $2+$ result showed gene amplication by fluorescent in situ hybridization (FISH). In FISH analyses, each copy of the HER2 gene and its centromere 17 (CEP17) reference were counted. The interpretation followed the criteria of the ASCO/CAP guidelines for HER2 IHC interpretation for breast cancer [38]: positive if the HER2/CEP17 ratio was higher than 2.2 . The cut-off for $\mathrm{p} 53$ was $\geq 1 \%$ positive tumor cells with nuclear staining. Ki67-labelling index $>30 \%$ was determined to be positive. E-cadherin antibody intensely stained the membrane and weakly stained the cytoplasm of cancer cells. E-cadherin expression was semi-quantitatively analyzed according to the percentage of cells showing membrane positivity: 0,0 to $10 \% ; 1+, 10$ to $30 \% ; 2+, 30$ to $70 \% ; 3+,>70 \%$. E-cadherin expression was considered positive when scores were $\geq 2$, and negative when scores were $\leq 1$. Cytoplasmic staining only was not included in the assessment. E- cadherin antibody intensely stained the membrane and weakly stained the cytoplasm of cancer cells. A case with cytoplasmic staining only was determined as E-cadherin negative, as shown with "score 0" (Figure 1).

\section{Statistical analysis}

Statistical analysis was performed using SPSS 13.0 statistical software (SPSS Inc, Chicago, IL, USA). We examined the association between TNBC and other clinicopathologic variables, and the significance of different prognostic markers using chi-squared test, and chisquared test for trend as appropriate. The association with survival was analyzed initially by Kaplan-Meier plot and log-rank test and also with Cox regression analysis to adjust for other prognostic indicators. A $P$-value of < 0.05 was considered significant. Cutoff values for different biomarkers included in this study were chosen before statistical analysis.

\section{Results}

The prognostic value of adjuvant chemotherapy in triplenegative breast cancer

Cases that were negative for ER, PR and HER2 expression were considered to be cases of TNBC. Among the total 1,036 breast cancer cases, there were 190 (18.3\%) cases of TNBC. Adjuvant chemotherapy was performed

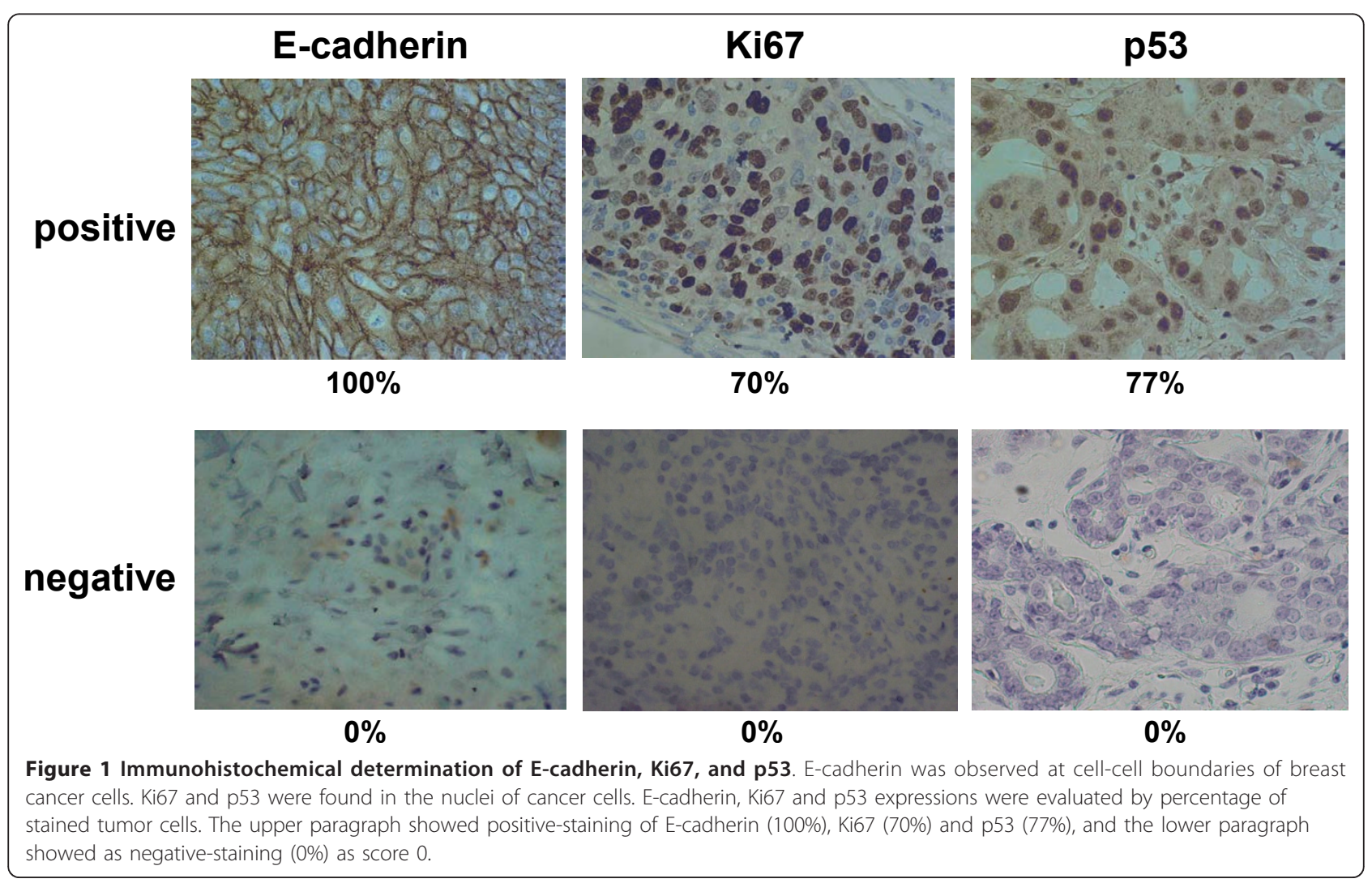


for $138(72.6 \%)$ of the 190 TNBC cases; 60 cases had an anthracyclin-based regimen and 78 a 5FU-based regimen (Table 1). The remaining 52 cases received surgery alone. Among the 190 TNBC cases, those receiving surgery plus adjuvant therapy $(n=138)$ had a more favorable prognosis $(P=0.0043)$ than those undergoing surgery alone $(n=52)$ (Figure $2 \mathrm{a})$. When restricting the analysis to patients with Stage II cancers, the overall survival of the surgery plus adjuvant chemotherapy group was significantly better than that of the surgery alone group $(P=0.0013)$ (Figure $2 \mathrm{~b})$. In contrast, in patients with Stage I and III cancers, no significant difference of overall survival was found between the surgery plus adjuvant chemotherapy group and the surgery alone group (Additional file 1). There was no significant difference in the prognosis of TNBC patients receiving adjuvant therapy between the anthracyclin-based regimen and 5FU-based regimen (Table 2).

\section{Significance of E-cadherin, Ki67, and p53 expression in triple-negative breast cancer}

Expression of E-cadherin, Ki67, and p53 was positive in 109 (57\%), $65(34 \%)$ and $118(62 \%)$ of 190 cases of TNBC, respectively (Table 3). The Ki67 expression level was significantly high in Stage II and III TNBC tumors (63\%, $P=0.013)$. No significant association between Ecadherin or p53 expression and clinicopathological parameters was identified in TNBC. The cases with E-cadherin-negative and Ki67-positive expression had a significantly higher incidence of lymph node metastasis (45\%, $P=0.027)$.

TNBC with reduced E-cadherin expression showed a significantly worse overall survival time $(P=0.0054$, logrank), and cases with Ki67 expression showed significantly worse overall survival time $(P=0.0181$, log-rank) (Figure 3a). Patients with E-cadherin-negative and Ki67positive expression showed a significantly worse overall

\begin{tabular}{|c|c|}
\hline Adjuvant chemotherapy regimen & $\begin{array}{c}\text { Number of } \\
\text { patients }\end{array}$ \\
\hline Anthracyclin-base & 60 \\
\hline fluorouracil+epirubicin+cyclophosphamide (FEC) & 34 \\
\hline epirubicin+cyclophosphamide (EC) & 12 \\
\hline adriamycin+cyclophosphamide (AC) & 11 \\
\hline cyclophosphamide+adriamycin+fluorouracil (CAF) & 3 \\
\hline non-Anthracyclin-base & 78 \\
\hline tegafur-uracil (UFT) & 61 \\
\hline $\begin{array}{l}\text { cyclophosphamide+methotorexate+fluorouracil } \\
\text { (CMF) }\end{array}$ & 10 \\
\hline doxifluridine (5'DFUR) & 4 \\
\hline fluorouracil (5FU) & 3 \\
\hline
\end{tabular}

survival time $(P=0.001, \log$-rank). The prognosis of the E-cadherin-negative cancer patients was significantly poorer than that of the E-cadherin-positive cancer patients in regard to overall survival at Stage II $(P=$ 0.0058) (Figure 3b). The prognosis of the combination of E-cadherin-negative and Ki67-positive expression cancer patients was significantly poorer than that of the combination of E-cadherin-positive and Ki67-negative expression cancer patients in regard to overall survival at Stage II $(P=0.0376)$ (Figure $3 b)$ and Stage I $(P=$ 0.0437) (Additional file 2). The combination of E-cadherin-negative and Ki67-positive expression was revealed to be a more significant prognostic indicator than either E-cadherin or Ki67 expression alone by multivariate analyses $(P=0.004$, OR $=2.784)$, while a univariate analysis revealed that the overall survival was significantly correlated with the E-cadherin expression, Ki67 expression, stage, tumor size and lymph node metastasis (Table 2).

In the 138 TNBC cases undergoing surgery plus adjuvant chemotherapy, the prognosis of patients with Ecadherin-negative plus Ki67-positive expression was significantly worse that the prognosis of patients with either of these risk factors alone $(P=0.001)$, while no significant difference in prognosis was found in the 52 TNBC cases undergoing surgery alone (Figure 4a). No significant difference in prognosis was found between the E-cadherin-negative and Ki67-positive cases undergoing surgery plus adjuvant chemotherapy $(n=51)$ and surgery alone cases. A multivariate logistic regression analysis showed that the combination of E-cadherinnegative and Ki67-positive expression was significantly correlated with the overall survival of patients undergoing surgery plus adjuvant chemotherapy $(P=0.001)$, but not in those undergoing surgery alone, suggesting that E-cadherin-negative and Ki67-positive expression is an independent prognostic factor for TNBC with adjuvant chemotherapy (Table 4 ). In the adjuvant chemotherapy group, the overall survival of TNBC patients having both E-cadherin-negative and Ki67-positive expression was significantly worse than that of patients with either risk factor alone at each of Stages II (Figure 4), I and III (Additional file 3). In contrast, no significant difference in prognosis in relation to the Ki67 expression and/or E-cadherin expression was found in 52 cases without adjuvant chemotherapy at each of Stages II (Figure 4), I and III (Additional file 3).

\section{Discussion}

Among the total 1,036 breast cancer cases, 190 (18.3\%) were cases of TNBC. NCCN guidelines and the St. Gallen consensus conference recommend adjuvant chemotherapy for TNBC [26], although a specific regimen for such adjuvant treatment has yet to be presented. In 


\section{A All cases $(n=190)$}

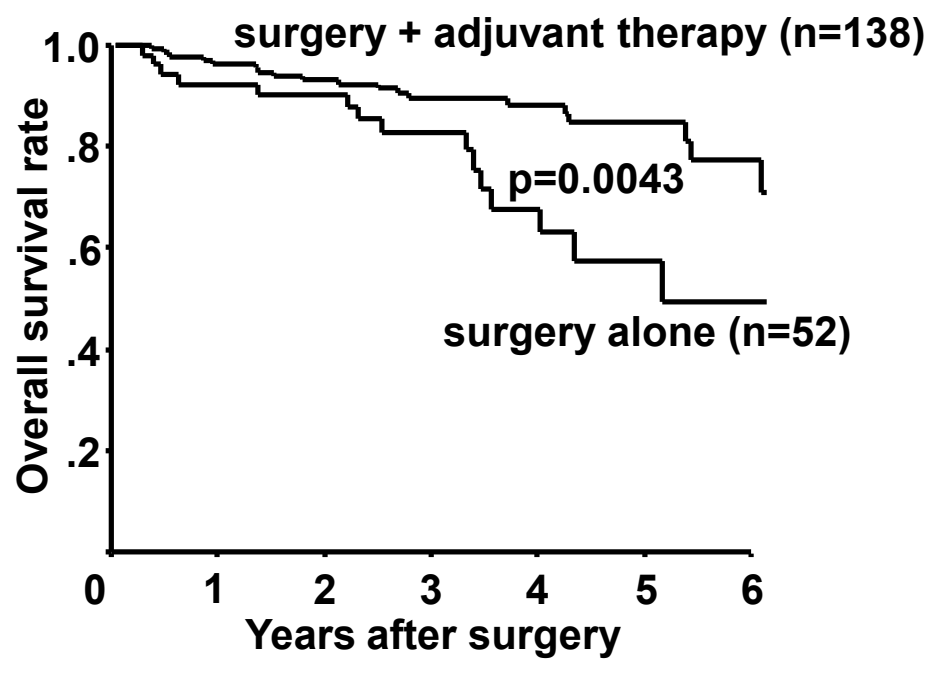

\section{B Stage II $(n=107)$}

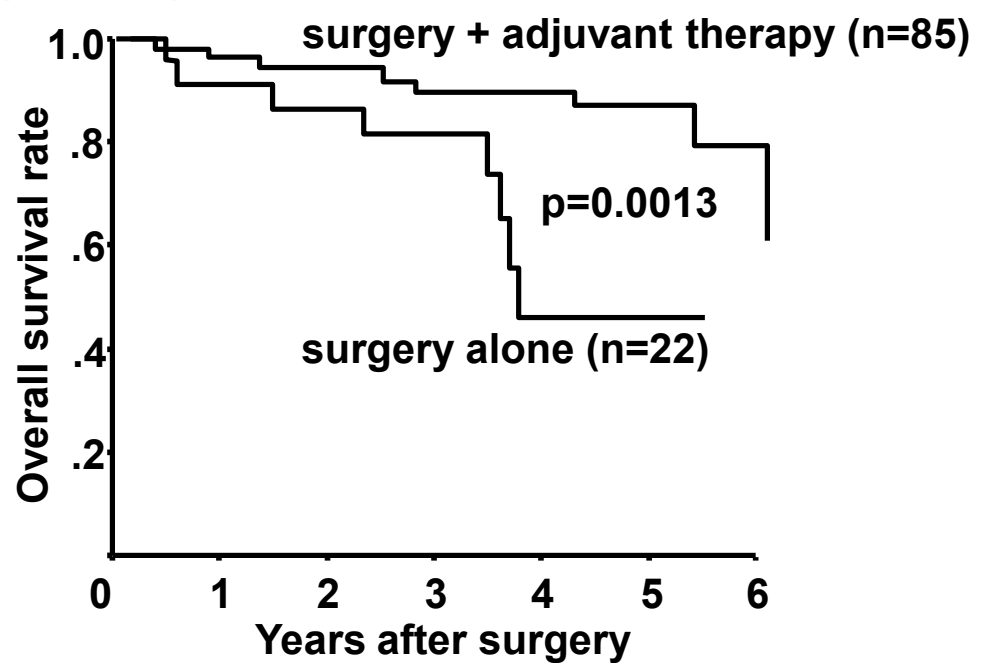

Figure 2 Overall survival of patients with triple-negative breast cancer according to receipt of adjuvant therapy. (A) Patients who underwent surgery plus adjuvant therapy showed a better prognosis than those who underwent surgery alone $(P=0.0043)$. (B) Prognosis of patients according to the clinical stage. Overall survival of patients by adjuvant chemotherapy was significantly better at Stage II $(P=0.0013)$.

the 190 TNBC cases of the present study, patients undergoing surgery plus adjuvant therapy had a more favorable prognosis than those receiving surgery alone, only among those with Stage II disease, suggesting that adjuvant therapy is indeed useful for TNBC patients as the NCCN recommends, and is most relevant at Stage II. In the adjuvant therapy group, both univariate and multivariate analysis showed no significant difference in prognosis between the anthracyclin-based regimen and 5FU-based regimen, although patients with the former regimen showed a trend-level improvement in prognosis over those with the latter. Larger studies might be necessary to clarify the prognoses of anthracyclin-based regimen and 5FU-based regimen.

Since reliable parameters to predict the chemosensitivity of TNBC have not been clinically available, the prognostic value of E-cadherin, Ki67 and p53 expression for the outcome of adjuvant chemotherapy was evaluated. In the adjuvant chemotherapy group, the prognosis of E-cadherin-negative and Ki67-positive patients was 
Table 2 Univariate and multivariate analysis with respect to overall survival in 190 triple-negative breast cancers

\begin{tabular}{|c|c|c|c|c|c|c|}
\hline \multirow[b]{2}{*}{ Parameters } & \multicolumn{3}{|c|}{ Univarite analysis } & \multicolumn{3}{|c|}{ Multivariate analysis } \\
\hline & Odds ratio & $95 \% \mathrm{Cl}$ & $P$-value & Odds ratio & $95 \% \mathrm{Cl}$ & $P$-value \\
\hline $\begin{array}{c}\text { Regimen } \\
\text { Anthracyclin-base vs 5FU-base }\end{array}$ & 0.38 & 0.13 to 1.08 & 0.068 & 0.46 & 0.15 to 1.38 & 0.164 \\
\hline \multicolumn{7}{|l|}{ E-cadherin } \\
\hline $\begin{array}{l}\text { Negative vs Positive } \\
\text { Ki67 }\end{array}$ & \multicolumn{5}{|c|}{ Ki67 } & 0.013 \\
\hline Negative vs Positive & 2.38 & 1.14 to 4.99 & 0.022 & 2.11 & 0.96 to 4.63 & 0.062 \\
\hline \multicolumn{7}{|l|}{ E-cadherin (-) and Ki67 (+) } \\
\hline Negative vs Positive & 3.03 & 1.54 to 5.98 & 0.001 & 2.78 & 1.38 to 5.60 & 0.004 \\
\hline \multicolumn{7}{|l|}{ p53 } \\
\hline Negative vs Positive & 1.60 & 0.75 to 3.42 & 0.229 & 1.13 & 0.51 to 2.52 & 0.758 \\
\hline \multicolumn{7}{|l|}{ Stage } \\
\hline 1 vs $2,3,4$ & 2.54 & 1.04 to 6.22 & 0.041 & 0.30 & 0.05 to 2.00 & 0.214 \\
\hline \multicolumn{7}{|l|}{ Tumor size } \\
\hline$\leq 2 \mathrm{~cm}$ vs $>2 \mathrm{~cm}$ & 2.46 & 1.11 to 5.45 & 0.027 & 3.25 & 0.75 to 14.15 & 0.116 \\
\hline \multicolumn{7}{|l|}{ Lymph node status } \\
\hline N0 vs N1, N2, N3 & 3.40 & 1.68 to 6.91 & 0.001 & 3.46 & 1.38 to 8.66 & 0.008 \\
\hline \multicolumn{7}{|l|}{ Lymph-vascular invasion } \\
\hline Negative vs Positive & 1.84 & 0.94 to 3.58 & 0.074 & 1.36 & 0.68 to 2.74 & 0.390 \\
\hline \multicolumn{7}{|l|}{ Nuclear grade } \\
\hline 1,2 , vs 3 & 2.36 & 1.07 to 5.21 & 0.034 & 1.93 & 0.58 to 6.39 & 0.282 \\
\hline
\end{tabular}

significantly worse than that of either E-cadherin-positive or Ki67-negative patients at all stages. Taking these results together, a multivariate logistic regression analysis showed that the E-cadherin-negative and Ki67-positive expression was significantly correlated with overall survival of patients receiving adjuvant chemotherapy. Ki67 is a candidate predictive marker for chemosensitivity in all types of breast cancer [16,26]; however, Ki67 alone is not an independent prognostic factor for TNBC with adjuvant chemotherapy. These findings suggested that the combination of E-cadherin and Ki67 expression could be of predictive value for TNBC patients treated by the adjuvant chemotherapeutic regimen, only at Stage II. On the other hand, in the group undergoing surgery alone, no significant difference of prognosis was found between E-cadherin-negative and Ki67-positive patients $(n=17)$ and either E-cadherin-positive or Ki67negative patients $(n=35)$. Since the combination of Ecadherin and Ki67 status might be a useful prognostic marker for adjuvant chemotherapy in TNBC patients, the adjuvant chemotherapy might have led to a better prognosis for the 35 cases with both E-cadherin-positive and Ki67-negative expression. In contrast, no significant difference in prognosis was found between the E-cadherin-negative and Ki67-positive cases undergoing surgery plus adjuvant chemotherapy and surgery alone cases, which might suggest that the development of new adjuvant treatment approaches is necessary for the Ecadherin-negative and Ki67-positive TNBC patients.
The Ki67 expression level was significantly high in Stages II and III TNBC tumors $(63 \%, P=0.013)$. These findings suggested that tumor cells at an advanced stage might have higher proliferative activity than those at an early stage.

The mechanisms responsible for the chemosensitivity of TNBC with E-cadherin-negative and Ki67-positive expression remain to be determined. Loss of E-cadherin induces epithelial-to-mesenchymal transition (EMT). EMT is a key step toward cancer metastasis. Ahmed et al. reported the close relationship between EMT and the cancer stem cell-like phenotype in response to chemoresistance [39]. Also, other studies have shown that Snail, Slug and Notch signaling, as EMT markers, were correlated with chemoresistance. These findings suggested that one of the possible mechanisms by which chemosensitivity is reduced in patients with TNBC with loss of E-cadherin expression may involve EMT signaling [22,37]. In contrast, several studies have reported that E-cadherin-dependent intercellular adhesion enhances chemoresistance [40-42]. The function of Ecadherin in the efficacy of chemotherapy is controversial. Further studies of the correlation between E-cadherin and chemosensitivity in TNBC might be necessary. Previous studies have demonstrated correlations between Ki67 expression and malignancy as well as patient outcomes $[43,44]$. Ki67 is one of the markers for chemosensitivity in breast carcinomas, but little correlation has been revealed between Ki67 expression and 


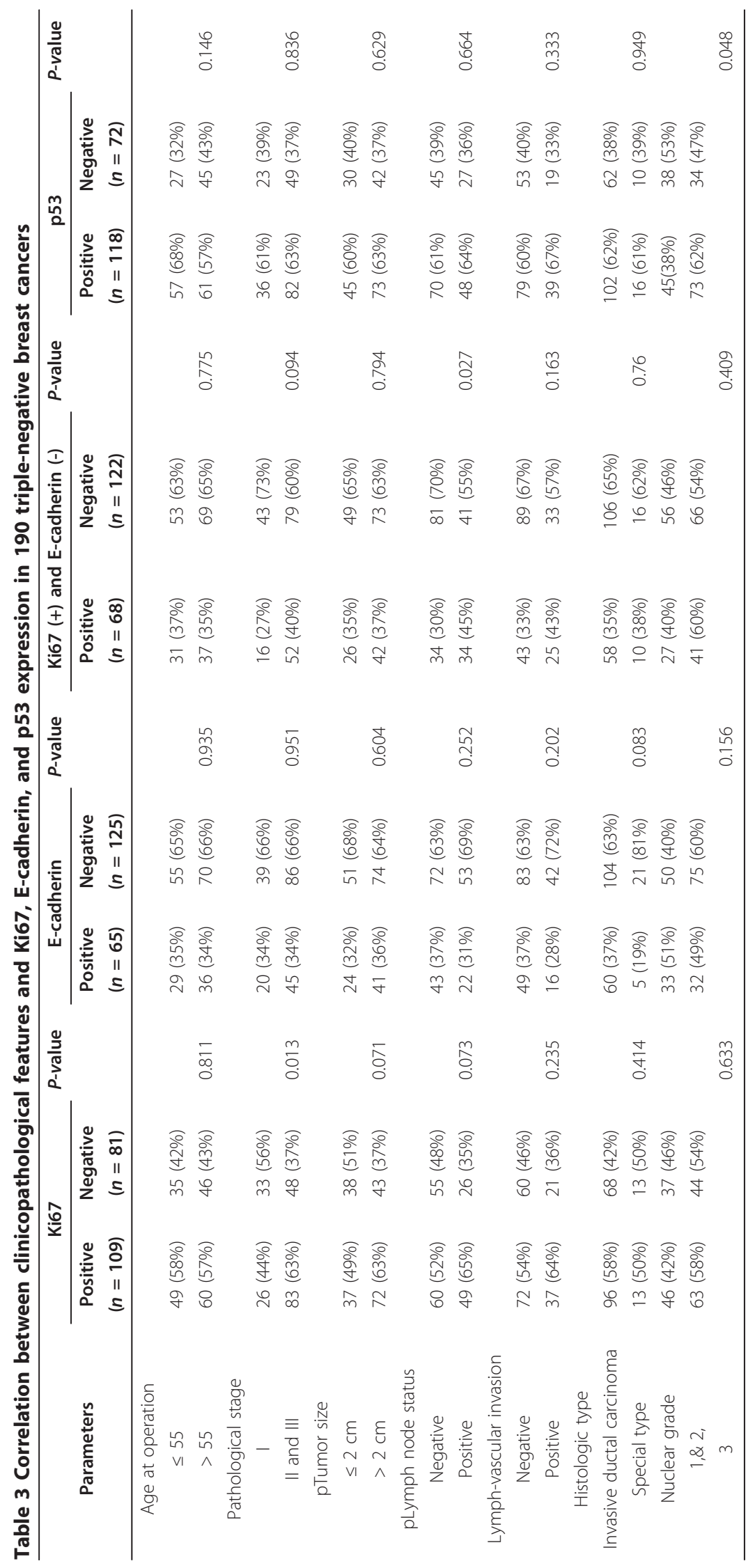




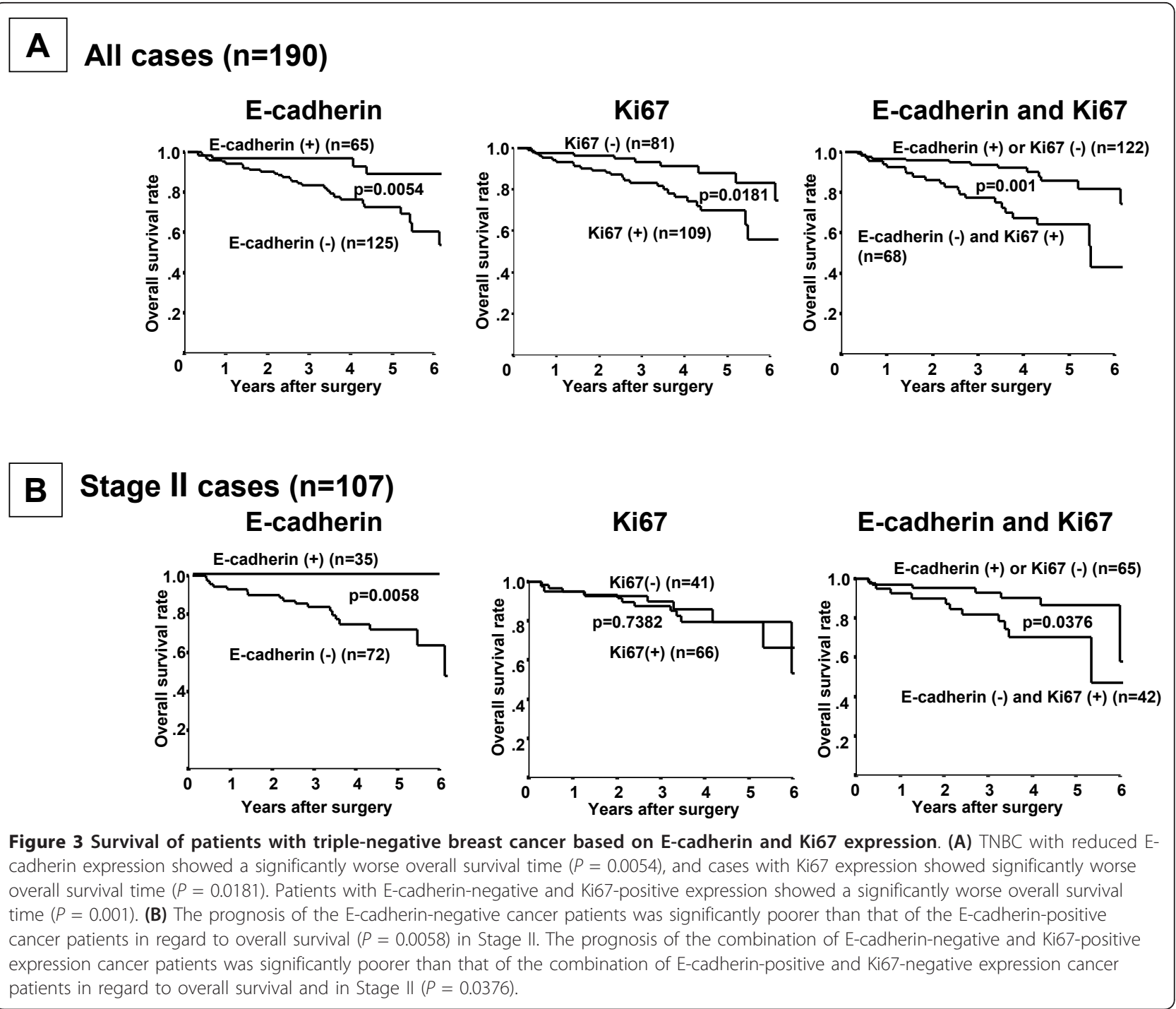

chemosensitivity in the triple-negative phenotype. In this study, we found that Ki67 expression had a prognostic value for the outcome of adjuvant chemotherapy in TNBC when it was combined with E-cadherin expression, but that Ki67 alone was not an independent prognostic factor.

CR Kennedy et al. reported that patients with TNBC who underwent adjuvant chemotherapy were less likely to die compared with those who received neoadjuvant chemotherapy or no chemotherapy. In contrast, our study reported that the adjuvant therapy is beneficial for Stage II TNBC patients. Moreover, we suggested that the combination of E-cadherin and Ki67 status might be a useful prognostic marker indicating the need for adjuvant chemotherapy in Stage II TNBC patients. These findings are novel in our study regarding the advantages of adjuvant chemotherapy. TNBC patients have a greater risk of distant metastasis $[45,46]$. The presence of micrometastasis in the bone marrow at the time of diagnosis of breast cancer is associated with a high risk of relapse and a poor prognosis $[47,48]$. Patients with bone marrow micrometastasis had tumors with a higher stage as defined by tumor size and lymph-node status, and hormone receptor-negative tumors [48-50]. These findings suggested that the observed survival benefit of adjuvant chemotherapy at Stage II may be a result of the decreased opportunity for systemic tumor shedding and growth of systemic micrometastases. Therefore, the benefit of primary tumor removal followed by adjuvant therapy may be clinically relevant for the TNBC at Stage II.

No significant difference of overall survival was found between the surgery alone group and the surgery plus adjuvant chemotherapy group at Stages I and III, while the surgery plus adjuvant therapy showed a better prognosis than the surgery alone (Additional file 


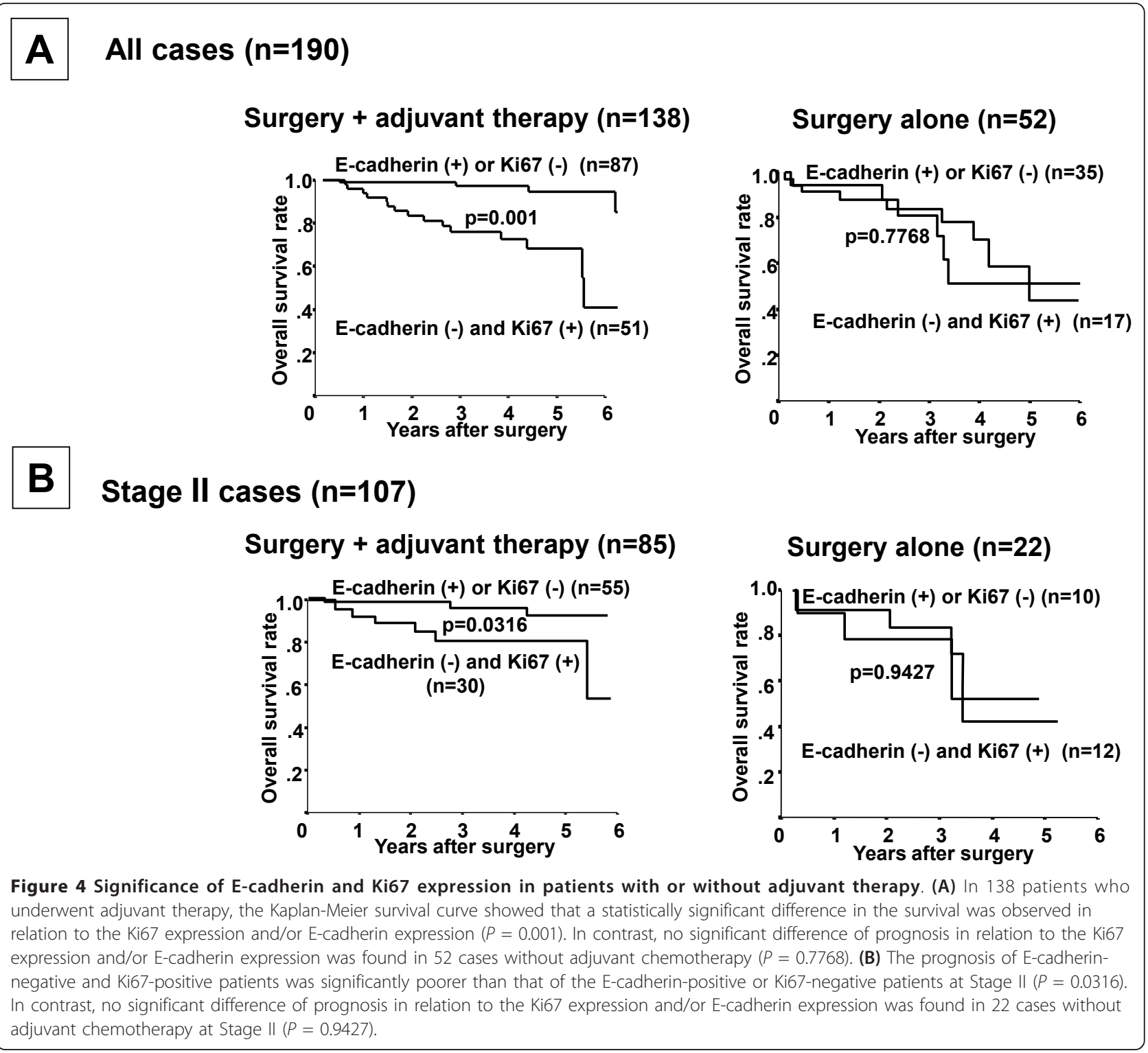

1). The recurrence rate of patients at Stage I was low and the sample size of patients at Stage III was small $(n=24)$ in this study, which might suggest one of the reasons why findings may be limited to Stage II. A larger number of TNBC patients with Stages I and III might be necessary to clarify whether patients with Stages I and III also have these advantages by adjuvant chemotherapy.

The p53 expression was positive in 118 (62\%) of 190 cases of TNBC in the present study, which was similar to previous reports of the p53 expression rate $(42 \%$ to $56 \%)$ in TNBC $[8,32,51]$. p53 status was not a specific prognostic factor in TNBC patients treated by adjuvant chemotherapy. There have been many studies on the predictive role of $\mathrm{p} 53$ for patients treated with anthracyclines, but most of these studies were performed in a neoadjuvant setting, and thus the value of p53 for predicting the efficacy of chemotherapy remains a matter of controversy $[27,28,30]$. Chae et al. reported that p53 status was a specific prognostic factor in 135 TNBC patients treated with an adjuvant anthracycline-based regimen, although, as the authors pointed out, the sample size was small [32]. Two of the main explanations for the discrepancies among these studies are that different methods were used to assess the p53 status, and the groups were different in terms of the patient characteristics and drug regimens. Because our study was also heterogeneous in terms of the 
Table 4 Univariate and multivariate analysis with respect to overall survival of 138 TNBC patients with surgery plus adjuvant chemotherapy or 52 TNBC patients with surgery alone

\begin{tabular}{|c|c|c|c|c|c|c|c|c|c|c|c|c|}
\hline \multirow[b]{3}{*}{ Parameters } & \multicolumn{7}{|c|}{ Patients with chemotherapy $(n=138)$} & \multicolumn{5}{|c|}{ Patients without chemotherapy $(n=52)$} \\
\hline & \multicolumn{4}{|c|}{ Univarite analysis } & \multicolumn{3}{|c|}{ Multivariate analysis } & \multicolumn{3}{|c|}{ Univarite analysis } & \multicolumn{2}{|c|}{$\begin{array}{c}\text { Multivariate } \\
\text { analysis }\end{array}$} \\
\hline & $\begin{array}{l}\text { Odds } \\
\text { ratio }\end{array}$ & $95 \% \mathrm{Cl}$ & $\begin{array}{c}P- \\
\text { value }\end{array}$ & $\begin{array}{l}\text { Odds } \\
\text { ratio }\end{array}$ & $95 \% \mathrm{Cl}$ & $\begin{array}{c}P- \\
\text { value }\end{array}$ & $\begin{array}{l}\text { Odds } \\
\text { ratio }\end{array}$ & $95 \% \mathrm{Cl}$ & $\begin{array}{c}p \\
\text { value }\end{array}$ & $\begin{array}{l}\text { Odds } \\
\text { ratio }\end{array}$ & $95 \% \mathrm{Cl}$ & $\begin{array}{c}P- \\
\text { value }\end{array}$ \\
\hline $\begin{array}{c}\text { Ki67 (+) and E- } \\
\text { cadherin (-) } \\
\text { Negative vs Positive }\end{array}$ & 6.69 & $\begin{array}{c}2.41 \text { to } \\
18.62\end{array}$ & $<0.001$ & 5.84 & $\begin{array}{c}2.03 \text { to } \\
16.76\end{array}$ & 0.001 & 1.16 & $\begin{array}{l}0.41 \text { to } \\
3.28\end{array}$ & 0.777 & 0.76 & $\begin{array}{l}0.20 \text { to } \\
2.94\end{array}$ & 0.688 \\
\hline $\begin{array}{c}\text { E-cadherin } \\
\text { Negative vs Positive }\end{array}$ & 0.02 & $\begin{array}{l}0.00 \text { to } \\
1.16\end{array}$ & 0.060 & 0.00 & $\begin{array}{l}0.00 \text { to } \\
1.98\end{array}$ & 0.943 & 1.00 & $\begin{array}{l}0.32 \text { to } \\
3.16\end{array}$ & 0.998 & 1.53 & $\begin{array}{l}0.44 \text { to } \\
5.36\end{array}$ & 0.503 \\
\hline $\begin{array}{c}\text { Ki67 } \\
\text { Negative vs Positive }\end{array}$ & 3.09 & $\begin{array}{l}1.11 \text { to } \\
8.66\end{array}$ & 0.032 & 2.60 & $\begin{array}{l}0.87 \text { to } \\
7.76\end{array}$ & 0.086 & 1.81 & $\begin{array}{l}0.62 \text { to } \\
5.31\end{array}$ & 0.282 & 1.89 & $\begin{array}{l}0.42 \text { to } \\
8.50\end{array}$ & 0.407 \\
\hline $\begin{array}{c}\text { p53 } \\
\text { Negative vs Positive }\end{array}$ & 1.61 & $\begin{array}{l}0.58 \text { to } \\
4.45\end{array}$ & 0.361 & 0.98 & $\begin{array}{l}0.34 \text { to } \\
2.85\end{array}$ & 0.975 & 1.61 & $\begin{array}{l}0.58 \text { to } \\
4.45\end{array}$ & 0.361 & 1.86 & $\begin{array}{l}0.54 \text { to } \\
6.45\end{array}$ & 0.327 \\
\hline $\begin{array}{c}\text { Stage } \\
1 \text { vs } 2,3,4\end{array}$ & 2.56 & $\begin{array}{l}0.73 \text { to } \\
8.99\end{array}$ & 0.144 & 0.15 & $\begin{array}{l}0.01 \text { to } \\
2.45\end{array}$ & 0.185 & 4.22 & $\begin{array}{l}1.17 \text { to } \\
15.28\end{array}$ & 0.028 & 1.28 & $\begin{array}{l}0.06 \text { to } \\
23.36\end{array}$ & 0.872 \\
\hline $\begin{array}{c}\text { Tumor size } \\
\leq 2 \mathrm{~cm} \text { vs }>2 \mathrm{~cm}\end{array}$ & 2.63 & $\begin{array}{l}0.86 \text { to } \\
8.01\end{array}$ & 0.089 & 4.23 & $\begin{array}{l}0.54 \text { to } \\
33.34\end{array}$ & 0.171 & 23.26 & $\begin{array}{l}1.02 \text { to } \\
10.38\end{array}$ & 0.046 & 1.65 & $\begin{array}{l}0.16 \text { to } \\
16.58\end{array}$ & 0.670 \\
\hline $\begin{array}{l}\text { Lymph node status } \\
\text { No vs N1, N2, N3 }\end{array}$ & 4.69 & $\begin{array}{l}1.67 \text { to } \\
13.16\end{array}$ & 0.003 & 5.71 & $\begin{array}{l}1.25 \text { to } \\
26.20\end{array}$ & 0.025 & 5.63 & $\begin{array}{l}1.68 \text { to } \\
18.93\end{array}$ & 0.005 & 5.10 & $\begin{array}{l}1.08 \text { to } \\
23.94\end{array}$ & 0.039 \\
\hline $\begin{array}{c}\text { Lymphvascular } \\
\text { invasion } \\
\text { Negative vs Positive }\end{array}$ & 2.09 & $\begin{array}{l}0.86 \text { to } \\
5.07\end{array}$ & 0.103 & 1.34 & $\begin{array}{l}0.52 \text { to } \\
3.44\end{array}$ & 0.548 & 1.32 & $\begin{array}{l}0.48 \text { to } \\
3.63\end{array}$ & 0.597 & 0.94 & $\begin{array}{l}0.29 \text { to } \\
3.09\end{array}$ & 0.922 \\
\hline $\begin{array}{c}\text { Nuclear grade } \\
1,2, \text { vs } 3\end{array}$ & 2.87 & $\begin{array}{l}0.94 \text { to } \\
8.72\end{array}$ & 0.063 & 1.64 & $\begin{array}{l}0.51 \text { to } \\
5.28\end{array}$ & 0.405 & 1.22 & $\begin{array}{c}0.39 \text { to } \\
3.86\end{array}$ & 0.732 & 0.99 & $\begin{array}{l}0.25 \text { to } \\
3.96\end{array}$ & 0.988 \\
\hline
\end{tabular}

chemotherapy regimen, a larger sample size with a single regimen might be necessary to evaluate the clinical significance of p53 for TNBC patients with adjuvant chemotherapy.

\section{Conclusions}

In conclusion, adjuvant therapy is beneficial for TNBC patients, only at Stage II. The combination of E-cadherin and Ki67 status might be a useful prognostic marker indicating the need for adjuvant chemotherapy in Stage II TNBC patients.

\section{Additional material}

Additional file 1: File showing overall survival of patients at Stages I and III according to receipt of adjuvant therapy. When restricting the analysis to patients with Stages I (A) and III (B) cancers, the overall survival of the surgery plus adjuvant chemotherapy group was not significantly better than that of the surgery alone group.

Additional file 2: File showing survival of patients at Stages I and III based on E-cadherin expression and Ki67 expression. (A) The prognosis of the combination of E-cadherin-negative and Ki67-positive expression cancer patients was significantly poorer than that of the combination of E-cadherin-positive and Ki67-negative expression cancer patients at Stage I $(P=0.0437)$. (B) In contrast, no significant difference was found at Stage III.

Additional file 3: File showing significance of E-cadherin and Ki67 expression in patients with or without adjuvant therapy. In surgery plus adjuvant chemotherapy group, the overall survival of TNBC patients having both E-cadherin-negative and Ki67-positive expression was significantly worse than that of patients with E-cadherin-positive and
Ki67-negative at Stages I and III. In contrast, no significant difference was found in surgery alone group.

\section{Abbreviations}

AC: adriamycin+cyclophosphamide; CAF: cyclophosphamide+adriamycin +fluorouracil; CEP 17: centromere 17; CMF: cyclophosphamide +methotorexate+fluorouracil; EC: epirubicin+cyclophosphamide; EMT: epithelial-to-mesenchymal transition; ER: estrogen receptor; FEC: fluorouracil +epirubicin+cyclophosphamide; FISH: fluorescent in situ hybridization; HER2: human epidermal growth factor receptor 2; IHC: Immunohistochemistry; NCCN: National Comprehensive Cancer Network; PR: progesterone receptor; TNBC: Triple-negative breast cancer; UFT: tegafur-uracil; 5'DFUR: doxifluridine; 5FU: 5-fluorouracil.

\section{Acknowledgements}

We thank Masako Shinkawa (Osaka City University Graduate School of Medicine) for helpful advice.

\section{Author details}

'Department of Surgical Oncology, Osaka City University Graduate School of Medicine, 1-4-3 Asahi-machi, Abeno-ku, Osaka, Japan. ${ }^{2}$ Oncology Institute of Geriatrics and Medical Science, Osaka City University Graduate School of Medicine, 1-4-3 Asahi-machi, Abeno-ku, Osaka, Japan. ${ }^{3}$ Department of Breastsurgical Oncology, Osaka City General Hospital, 2-13-22 Miyakojima-hondori, Osaka, Japan.

\section{Authors' contributions}

SK participated in study concepts, study design, data analysis and interpretation, and prepared and edited the manuscript. MY participated in study concepts, study design, quality control of data and algorithms, and in the preparation, editing and review of the manuscript. $\Pi$ took part in data acquisition and statistical analysis. NA participated in data analysis and interpretation, and statistical analysis. $\mathrm{KI}$ and $\mathrm{YO}$ took part in data acquisition. $\mathrm{TI}$ and $\mathrm{KH}$ reviewed the manuscript. All authors read and approved the final manuscript 


\section{Competing interests}

The authors declare that they have no competing interests.

Received: 21 February 2011 Revised: 14 June 2011

Accepted: 30 November 2011 Published: 30 November 2011

\section{References}

1. Sorlie T, Tibshirani R, Parker J, Hastie T, Marron JS, Nobel A, Deng S, Johnsen H, Pesich R, Geisler S, Demeter J, Perou CM, Lonning PE, Brown PO, Borresen-Dale AL, Botstein D: Repeated observation of breast tumor subtypes in independent gene expression data sets. Proc Natl Acad Sci USA 2003, 100:8418-8423.

2. Rakha EA, El-Rehim DA, Paish C, Green AR, Lee AH, Robertson JF, Blamey RW, Macmillan D, Ellis IO: Basal phenotype identifies a poor prognostic subgroup of breast cancer of clinical importance. Eur J Cancer 2006, 42:3149-3156.

3. Bauer KR, Brown M, Cress RD, Parise CA, Caggiano V: Descriptive analysis of estrogen receptor (ER)-negative, progesterone receptor (PR)-negative, and HER2-negative invasive breast cancer, the so-called triple-negative phenotype: a population-based study from the California cancer Registry. Cancer 2007, 109:1721-1728.

4. Perou CM, Sorlie T, Eisen MB, van de Rijn M, Jeffrey SS, Rees CA, Pollack JR, Ross DT, Johnsen $H$, Akslen LA, Fluge O, Pergamenschikov A, Williams $C$, Zhu SX, Lonning PE, Borresen-Dale AL, Brown PO, Botstein D: Molecular portraits of human breast tumours. Nature 2000, 406:747-752.

5. Abd El-Rehim DM, Ball G, Pinder SE, Rakha E, Paish C, Robertson JF, Macmillan D, Blamey RW, Ellis IO: High-throughput protein expression analysis using tissue microarray technology of a large well-characterised series identifies biologically distinct classes of breast cancer confirming recent CDNA expression analyses. Int J Cancer 2005, 116:340-350.

6. Mattie MD, Benz CC, Bowers J, Sensinger K, Wong L, Scott GK, Fedele V, Ginzinger D, Getts R, Haqq C: Optimized high-throughput microRNA expression profiling provides novel biomarker assessment of clinical prostate and breast cancer biopsies. Mol Cancer 2006, 5:24.

7. Sorlie T, Perou CM, Tibshirani R, Aas T, Geisler S, Johnsen H, Hastie T, Eisen MB, van de Rijn M, Jeffrey SS, Thorsen T, Quist H, Matese JC, Brown PO, Botstein D, Eystein Lonning P, Borresen-Dale AL: Gene expression patterns of breast carcinomas distinguish tumor subclasses with clinical implications. Proc Natl Acad Sci USA 2001, 98:10869-10874.

8. Rakha EA, El-Sayed ME, Green AR, Lee AH, Robertson JF, Ellis IO: Prognostic markers in triple-negative breast cancer. Cancer 2007, 109:25-32.

9. Carey LA, Perou CM, Livasy CA, Dressler LG, Cowan D, Conway K, Karaca G, Troester MA, Tse CK, Edmiston S, Deming SL, Geradts J, Cheang MC Nielsen TO, Moorman PG, Earp HS, Millikan RC: Race, breast cancer subtypes, and survival in the Carolina Breast Cancer Study. JAMA 2006, 295:2492-2502.

10. Perez EA, Moreno-Aspitia A, Aubrey Thompson E, Andorfer CA: Adjuvant therapy of triple negative breast cancer. Breast Cancer Res Treat 2010, 120:285-291

11. Gluz O, Liedtke C, Gottschalk N, Pusztai L, Nitz U, Harbeck N: Triplenegative breast cancer-current status and future directions. Ann Oncol 2009, 20:1913-1927.

12. Rastogi P, Anderson SJ, Bear HD, Geyer CE, Kahlenberg MS, Robidoux A, Margolese RG, Hoehn JL, Vogel VG, Dakhil SR, Tamkus D, King KM, Pajon ER, Wright MJ, Robert J, Paik S, Mamounas EP, Wolmark N: Preoperative chemotherapy: updates of National Surgical Adjuvant Breast and Bowel Project Protocols B-18 and B-27. J Clin Oncol 2008, 26:778-785.

13. Kennedy CR, Gao F, Margenthaler JA: Neoadjuvant versus adjuvant chemotherapy for triple negative breast cancer. J Surg Res 2010, 163:52-57.

14. Stebbing J, Ellis $P$, Tutt A: PARP inhibitors in BRCA1-/BRCA2-associated and triple-negative breast cancers. Future Oncol 2010, 6:485-486.

15. Comen EA, Robson M: Poly(ADP-ribose) polymerase inhibitors in triplenegative breast cancer. Cancer J 2010, 16:48-52.

16. Dowsett M, Houghton J, Iden C, Salter J, Farndon J, A'Hern R, Sainsbury R, Baum M: Benefit from adjuvant tamoxifen therapy in primary breast cancer patients according oestrogen receptor, progesterone receptor, EGF receptor and HER2 status. Ann Oncol 2006, 17:818-826.

17. Derksen PW, Liu X, Saridin F, van der Gulden H, Zevenhoven J, Evers B, van Beijnum JR, Griffioen AW, Vink J, Krimpenfort P, Peterse JL, Cardiff RD, Berns A, Jonkers J: Somatic inactivation of E-cadherin and p53 in mice leads to metastatic lobular mammary carcinoma through induction of anoikis resistance and angiogenesis. Cancer Cell 2006, 10:437-449.

18. Meiners S, Brinkmann V, Naundorf H, Birchmeier W: Role of morphogenetic factors in metastasis of mammary carcinoma cells. Oncogene 1998, 16:9-20.

19. Charpin C, Garcia S, Bonnier P, Martini F, Andrac L, Choux R, Lavaut MN, Allasia C: Reduced E-cadherin immunohistochemical expression in nodenegative breast carcinomas correlates with 10-year survival. Am J Clin Pathol 1998, 109:431-438.

20. Heimann $R$, Lan F, McBride R, Hellman S: Separating favorable from unfavorable prognostic markers in breast cancer: the role of E-cadherin. Cancer Res 2000, 60:298-304.

21. Siitonen SM, Kononen JT, Helin HJ, Rantala IS, Holli KA, Isola JJ: Reduced Ecadherin expression is associated with invasiveness and unfavorable prognosis in breast cancer. Am J Clin Pathol 1996, 105:394-402.

22. Mahler-Araujo B, Savage K, Parry S, Reis-Filho JS: Reduction of E-cadherin expression is associated with non-lobular breast carcinomas of basal-like and triple negative phenotype. J Clin Pathol 2008, 61:615-620.

23. Fricke E, Hermannstadter C, Keller G, Fuchs M, Brunner I, Busch R, Hofler H, Becker KF, Luber B: Effect of wild-type and mutant E-cadherin on cell proliferation and responsiveness to the chemotherapeutic agents cisplatin, etoposide, and 5-fluorouracil. Oncology 2004, 66:150-159.

24. Graziano F, Mandolesi A, Ruzzo A, Bearzi I, Testa E, Arduini F, Silva R, Muretto P, Mari D, Berardi R, Scartozzi M, Lai V, Cascinu S, Magnani M: Predictive and prognostic role of E-cadherin protein expression in patients with advanced gastric carcinomas treated with palliative chemotherapy. Tumour Biol 2004, 25:106-110.

25. Koo JS, Jung $\mathrm{W}$, Jeong J: The predictive role of E-cadherin and androgen receptor on in vitro chemosensitivity in triple-negative breast Cancer. Jpn J Clin Oncol 2009, 39:560-568.

26. Goldhirsch A, Wood WC, Gelber RD, Coates AS, Thurlimann B, Senn HJ: Progress and promise: highlights of the international expert consensus on the primary therapy of early breast cancer 2007. Ann Oncol 2007, 18:1133-1144.

27. Makris A, Powles TJ, Dowsett M, Osborne CK, Trott PA, Fernando IN, Ashley SE, Ormerod MG, Titley JC, Gregory RK, Allred DC: Prediction of response to neoadjuvant chemoendocrine therapy in primary breast carcinomas. Clin Cancer Res 1997, 3:593-600.

28. Rozan S, Vincent-Salomon A, Zafrani B, Validire P, De Cremoux P, Bernoux A, Nieruchalski M, Fourquet A, Clough K, Dieras V, Pouillart P, Sastre-Garau X: No significant predictive value of c-erbB-2 or p53 expression regarding sensitivity to primary chemotherapy or radiotherapy in breast cancer. Int J Cancer 1998, 79:27-33.

29. Mathieu MC, Koscielny S, Le Bihan ML, Spielmann M, Arriagada R: p53 protein overexpression and chemosensitivity in breast cancer. Institut Gustave-Roussy Breast Cancer Group. Lancet 1995, 345:1182.

30. Geisler S, Lonning PE, Aas T, Johnsen H, Fluge O, Haugen DF, Lillehaug JR, Akslen LA, Borresen-Dale AL: Influence of TP53 gene alterations and CerbB-2 expression on the response to treatment with doxorubicin in locally advanced breast cancer. Cancer Res 2001, 61:2505-2512.

31. Berns EM, Foekens JA, Vossen R, Look MP, Devilee P, Henzen-Logmans SC, van Staveren IL, van Putten WL, Inganas M, Meijer-van Gelder ME, Cornelisse C, Claassen CJ, Portengen H, Bakker B, Klijn JG: Complete sequencing of TP53 predicts poor response to systemic therapy of advanced breast cancer. Cancer Res 2000, 60:2155-2162.

32. Chae BJ, Bae JS, Lee A, Park WC, Seo YJ, Song BJ, Kim JS, Jung SS: p53 as a specific prognostic factor in triple-negative breast cancer. Jpn J Clin Oncol 2009, 39:217-224.

33. Faneyte IF, Schrama JG, Peterse JL, Remijnse PL, Rodenhuis S, van de Vijver MJ: Breast cancer response to neoadjuvant chemotherapy: predictive markers and relation with outcome. $\mathrm{Br} J$ Cancer 2003, 88:406-412.

34. Rakha EA, Patel A, Powe DG, Benhasouna A, Green AR, Lambros MB, ReisFilho JS, Ellis IO: Clinical and biological significance of E-cadherin protein expression in invasive lobular carcinoma of the breast. Am J Surg Pathol 2010, 34:1472-1479.

35. Singletary SE, Greene FL: Revision of breast cancer staging: the 6th edition of the TNM Classification. Semin Surg Oncol 2003, 21:53-59.

36. Bevers TB, Anderson BO, Bonaccio E, Buys S, Daly MB, Dempsey PJ, Farrar WB, Fleming I, Garber JE, Harris RE, Heerdt AS, Helvie M, Huff JG, Khakpour N, Khan SA, Krontiras H, Lyman G, Rafferty E, Shaw S, Smith ML, 
Tsangaris TN, Williams C, Yankeelov T, National Comprehensive Cancer Network: NCCN clinical practice guidelines in oncology: breast cancer screening and diagnosis. J Natl Compr Canc Netw 2009, 7:1060-1096.

37. Kashiwagi S, Yashiro M, Takashima T, Nomura S, Noda S, Kawajiri H, Ishikawa T, Wakasa K, Hirakawa K: Significance of E-cadherin expression in triple-negative breast cancer. Br J Cancer 2010, 103:249-255.

38. Wolff AC, Hammond ME, Schwartz JN, Hagerty KL, Allred DC, Cote RJ, Dowsett M, Fitzgibbons PL, Hanna WM, Langer A, McShane LM, Paik S, Pegram MD, Perez EA, Press MF, Rhodes A, Sturgeon C, Taube SE, Tubbs R, Vance GH, van de Vijver M, Wheeler TM, Hayes DF: American Society of Clinical Oncology/College of American Pathologists guideline recommendations for human epidermal growth factor receptor 2 testing in breast cancer. J Clin Oncol 2007, 25:118-145.

39. Ahmed N, Abubaker K, Findlay J, Quinn M: Epithelial mesenchymal transition and cancer stem cell-like phenotypes facilitate chemoresistance in recurrent ovarian cancer. Curr Cancer Drug Targets 2010, 10:268-278.

40. Nakamura T, Kato Y, Fuji H, Horiuchi T, Chiba Y, Tanaka K: E-cadherindependent intercellular adhesion enhances chemoresistance. Int J Mol Med 2003, 12:693-700.

41. Kang HG, Jenabi JM, Zhang J, Keshelava N, Shimada H, May WA, Ng T, Reynolds CP, Triche TJ, Sorensen PH: E-cadherin cell-cell adhesion in ewing tumor cells mediates suppression of anoikis through activation of the ErbB4 tyrosine kinase. Cancer Res 2007, 67:3094-3105.

42. Green SK, Francia G, Isidoro C, Kerbel RS: Antiadhesive antibodies targeting E-cadherin sensitize multicellular tumor spheroids to chemotherapy in vitro. Mol Cancer Ther 2004, 3:149-159.

43. Yerushalmi R, Woods R, Ravdin PM, Hayes MM, Gelmon KA: Ki67 in breast cancer: prognostic and predictive potential. Lancet Oncol 2010, 11:174-183.

44. Lopez M, Di Lauro L, Viola G, Foggi P, Conti F, Corsetti S, Sergi D, Botti C, Di Filippo F, Vici P: [Adjuvant chemotherapy in hormone-receptor positive HER2-negative early breast cancer]. Clin Ter 2009, 160:481-488.

45. Nguyen PL, Taghian AG, Katz MS, Niemierko A, Abi Raad RF, Boon WL, Bellon JR, Wong JS, Smith BL, Harris JR: Breast cancer subtype approximated by estrogen receptor, progesterone receptor, and HER-2 is associated with local and distant recurrence after breast-conserving therapy. J Clin Oncol 2008, 26:2373-2378.

46. Kennecke H, Yerushalmi R, Woods R, Cheang MC, Voduc D, Speers CH, Nielsen TO, Gelmon K: Metastatic behavior of breast cancer subtypes. J Clin Oncol 2010, 28:3271-3277.

47. Wiedswang G, Borgen E, Karesen R, Kvalheim G, Nesland JM, Qvist H, Schlichting E, Sauer T, Janbu J, Harbitz T, Naume B: Detection of isolated tumor cells in bone marrow is an independent prognostic factor in breast cancer. J Clin Oncol 2003, 21:3469-3478.

48. Braun S, Pantel K, Muller P, Janni W, Hepp F, Kentenich CR, Gastroph S, Wischnik A, Dimpfl T, Kindermann G, Riethmuller G, Schlimok G: Cytokeratin-positive cells in the bone marrow and survival of patients with stage I, II, or III breast cancer. N Engl J Med 2000, 342:525-533.

49. Braun S, Vogl FD, Naume B, Janni W, Osborne MP, Coombes RC, Schlimok G, Diel IJ, Gerber B, Gebauer G, Pierga JY, Marth C, Oruzio D, Wiedswang G, Solomayer EF, Kundt G, Strobl B, Fehm T, Wong GY, Bliss J, Vincent-Salomon A, Pantel K: A pooled analysis of bone marrow micrometastasis in breast cancer. N Engl J Med 2005, 353:793-802.

50. Diel IJ, Kaufmann M, Costa SD, Holle R, von Minckwitz G, Solomayer EF, Kaul S, Bastert G: Micrometastatic breast cancer cells in bone marrow at primary surgery: prognostic value in comparison with nodal status. $J$ Natl Cancer Inst 1996, 88:1652-1658.

51. Bidard FC, Matthieu MC, Chollet P, Raoefils I, Abrial C, Domont J, Spielmann M, Delaloge S, Andre F, Penault-Llorca F: p53 status and efficacy of primary anthracyclines/alkylating agent-based regimen according to breast cancer molecular classes. Ann Oncol 2008, 19:1261-1265

doi:10.1186/bcr3068

Cite this article as: Kashiwagi et al:: Advantages of adjuvant chemotherapy for patients with triple-negative breast cancer at Stage II: usefulness of prognostic markers E-cadherin and Ki67. Breast Cancer Research 2011 13:R122.

\section{Submit your next manuscript to BioMed Central and take full advantage of:}

- Convenient online submission

- Thorough peer review

- No space constraints or color figure charges

- Immediate publication on acceptance

- Inclusion in PubMed, CAS, Scopus and Google Scholar

- Research which is freely available for redistribution

Submit your manuscript at www.biomedcentral.com/submit
Biomed Central 